\title{
The Effects of Cyanide, Azide, Carbon Monoxide and Salicylhydroxamic Acid on Whole-cell Respiration of Acanthamoeba castellanii
}

\author{
By DAVID LLOYD, ${ }^{1 *}$ BODIL KRISTENSEN ${ }^{2}$ AND HANS DEGN ${ }^{2}$ \\ ${ }^{1}$ Department of Microbiology, University College, Newport Road, Cardiff CF2 1TA, U.K. \\ ${ }^{2}$ Institute of Biochemistry, Odense University, DK-5230, Odense M, Denmark
}

(Received 1 May 1981; revised 18 June 1981)

Both early- and late-exponential phase cells of Acanthamoeba castellanii possess a terminal oxidase which is inhibited by $1 \mathrm{~mm}$-cyanide but not by azide, salicylhydroxamic acid or $\mathrm{CO}$. In early-exponential phase organisms this oxidase has a low affinity for $\mathrm{O}_{2}$, but in late-exponential phase organisms it is modified or replaced by an oxidase which can function rapidly at around $1 \mu \mathrm{M}-\mathrm{O}_{2}$.

\section{INTRODUCTION}

In many micro-organisms subsidiary terminal oxidases may function as alternatives to the main respiratory chain oxidase (Degn et al., 1978); the existence of these alternative oxidases is demonstrated by studies of the effects of different respiratory inhibitors on mitochondrial and whole-cell respiration. In the soil amoeba Acanthamoeba castellanii evidence has been presented for three different mitochondrial terminal oxidases (Edwards \& Lloyd 1977, $1978 a, b$; Lloyd et al., 1979): (1) cytochrome $a a_{3}$, inhibited by azide, $\mathrm{CO}$ and cyanide; (2) an oxidase inhibited by salicylhydroxamic acid (SHAM); and (3) an oxidase inhibited by cyanide, but not by azide or SHAM, which has a low affinity for $\mathrm{O}_{2}$ (apparent $K_{\mathrm{m}}>$ $\left.7 \mu \mathrm{M}-\mathrm{O}_{2}\right)$. The present study confirms the presence of these three distinct oxidases in early-exponential phase organisms and shows that oxidase (3) is not inhibited by CO. The use of mass spectrometry to measure respiration at low $\mathrm{O}_{2}$ concentrations $(<1 \mu \mathrm{M})$ indicates either that the affinity of oxidase (3) for oxygen is increased in cells from late-exponential phase cultures, or that it is replaced by a fourth oxidase.

\section{METHODS}

Maintenance and growth of organisms. Acanthamoeba castellanii was maintained and grown axenically with shaking at $30^{\circ} \mathrm{C}$ in a medium containing $(\%, w / v)$ : Difco proteose peptone, 0.75 ; Oxoid yeast extract, 0.75 ; glucose, 1.5. Organisms were counted in a Fuchs-Rosenthal haemocytometer slide (Baird \& Tatlock, Chadwell Heath, Romford, Essex, U.K.) after suitable dilution in distilled water.

Measurements of $\mathrm{O}_{2}$ consumption rates. Measurements of respiration were made in stirred open reaction systems at $30^{\circ} \mathrm{C}$ by two different methods: (1) in a membrane-covered oxygen electrode (Degn et al., 1980), or (2) using a quadrupole mass spectrometer with a membrane inlet (Lloyd et al., 1981). The latter apparatus allows the simultaneous measurement of $\mathrm{O}_{2}$ and $\mathrm{CO}$ in solution. $\mathrm{CO}$ was measured as a minor peak at mass 12 because its major peak at mass 28 coincides with that of $\mathrm{N}_{2}$.

Inhibitors. Fixed concentrations of $\mathrm{CO}$ in reaction mixtures were established by mixing fixed proportions with $\mathrm{N}_{2}$ and allowing the resulting mixtures to enter the air $/ \mathrm{N}_{2}$ gas stream to the open reaction vessel (Petersen, 1977). $\mathrm{KCN}$ and $\mathrm{NaN}_{3}$ were used as aqueous solutions ( $\mathrm{pH}$ 7.4). SHAM was dissolved in ethanol. Inhibition (\%) is expressed relative to the respiration rate in the absence of any inhibitor.

\section{RESULTS AND DISCUSSION}

The effects of inhibitors of respiration on steady-state concentrations of dissolved $\mathrm{O}_{2}$ in growing cultures of $A$. castellanii are shown in Fig. 1. In early-exponential phase cultures 


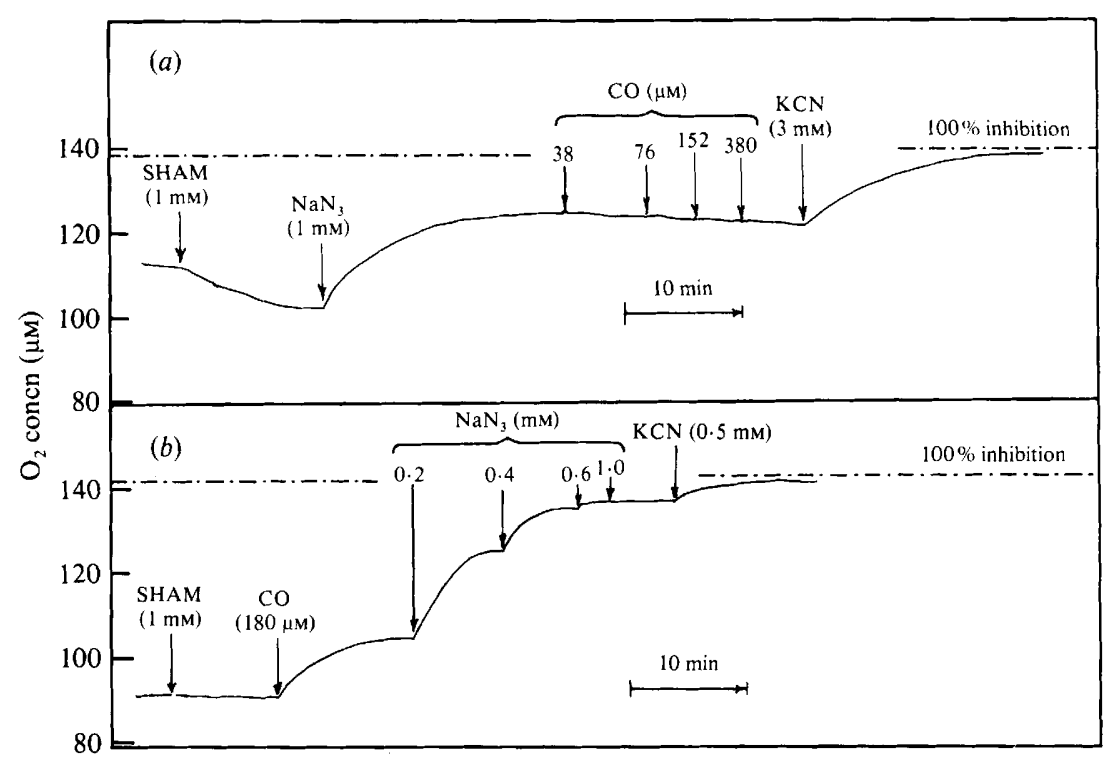

Fig. 1. Polarographic determination of the effects of respiratory inhibitors on steady-state $\mathrm{O}_{2}$ concentrations in cultures of Acanthamoeba castellanii. (a) An early-exponential phase culture $(2 \cdot 3 \times$ $10^{5}$ organisms $\left.\mathrm{ml}^{-1}\right)$ concentrated 20 -fold. (b) A late-exponential phase culture $\left(1.2 \times 10^{6}\right.$ organisms $\mathrm{ml}^{-1}$ ) concentrated 4-fold. Measurements were made in the open electrode system on organisms in $4.5 \mathrm{ml}$ growth medium; the results are typical of triplicate experiments. Constant partial pressure of $\mathrm{O}_{2}$ $(160 \mu \mathrm{M})$ in the gas phase was monitored with a second electrode.

(Fig. 1a), addition of $1 \mathrm{mM}$-SHAM stimulated respiration: this confirms the earlier observations of Edwards \& Lloyd (1977), who have discussed possible mechanisms involved in cyanide- or SHAM-stimulated respiration. In the presence of SHAM, azide effectively blocks the main phosphorylating electron transport chain of mitochondria (Lloyd et al., 1979); in the experiment shown, inhibition of this pathway by $1 \mathrm{mM}$-azide (together with the inhibited SHAM-sensitive pathway) accounted for only $60 \%$ of the total respiration. Equilibration with up to $380 \mu \mathrm{M}-\mathrm{CO}$ (at $120 \mu \mathrm{M}-\mathrm{O}_{2}$ ) gave no additional inhibition of respiration, indicating that any oxidase sensitive to $\mathrm{CO}$ had already been inhibited by azide. However, inhibition of the SHAM-sensitive oxidase and cytochrome $a_{3}$ did not account for all of the cyanide-sensitive respiration; the remaining $40 \%$ of the total respiration was almost completely inhibited on further addition of $3 \mathrm{mM}-\mathrm{KCN}$.

The response of the respiration of organisms of late-exponential phase cultures to inhibitors was markedly different (Fig. 1b). As previously demonstrated (Edwards \& Lloyd, 1977), addition of $1 \mathrm{~mm}$-SHAM produced no measurable effect; almost all of the electron flux is by way of the major terminal oxidase (cytochrome $a_{3}$ ) in these cells. The effect of $180 \mu \mathrm{M}$-CO was to give only partial inhibition of this oxidase ( $25 \%$ of total respiration), as would be expected at high $\mathrm{O}_{2}$ concentrations for a competitive inhibitor. The subsequent addition of azide gave a far greater extent of inhibition of cytochrome $a_{3}$; only $11 \%$ of the total respiration then remained, and this portion was cyanide-sensitive (mediated by oxidase 3 ). These results were typical of those obtained in 12 experiments in which all possible sequences of inhibitor additions were explored. Similar results were obtained with growing cultures and with washed cell suspensions. It was concluded that in high $\mathrm{O}_{2}$ concentrations (in the range $80-140 \mu \mathrm{M}$ ), cyanide was the most effective inhibitor, followed by azide, with $\mathrm{CO}$ least effective. The presence of SHAM (especially in the case of organisms from early-exponential phase cultures) was necessary to obtain maximal effects of these inhibitors. 


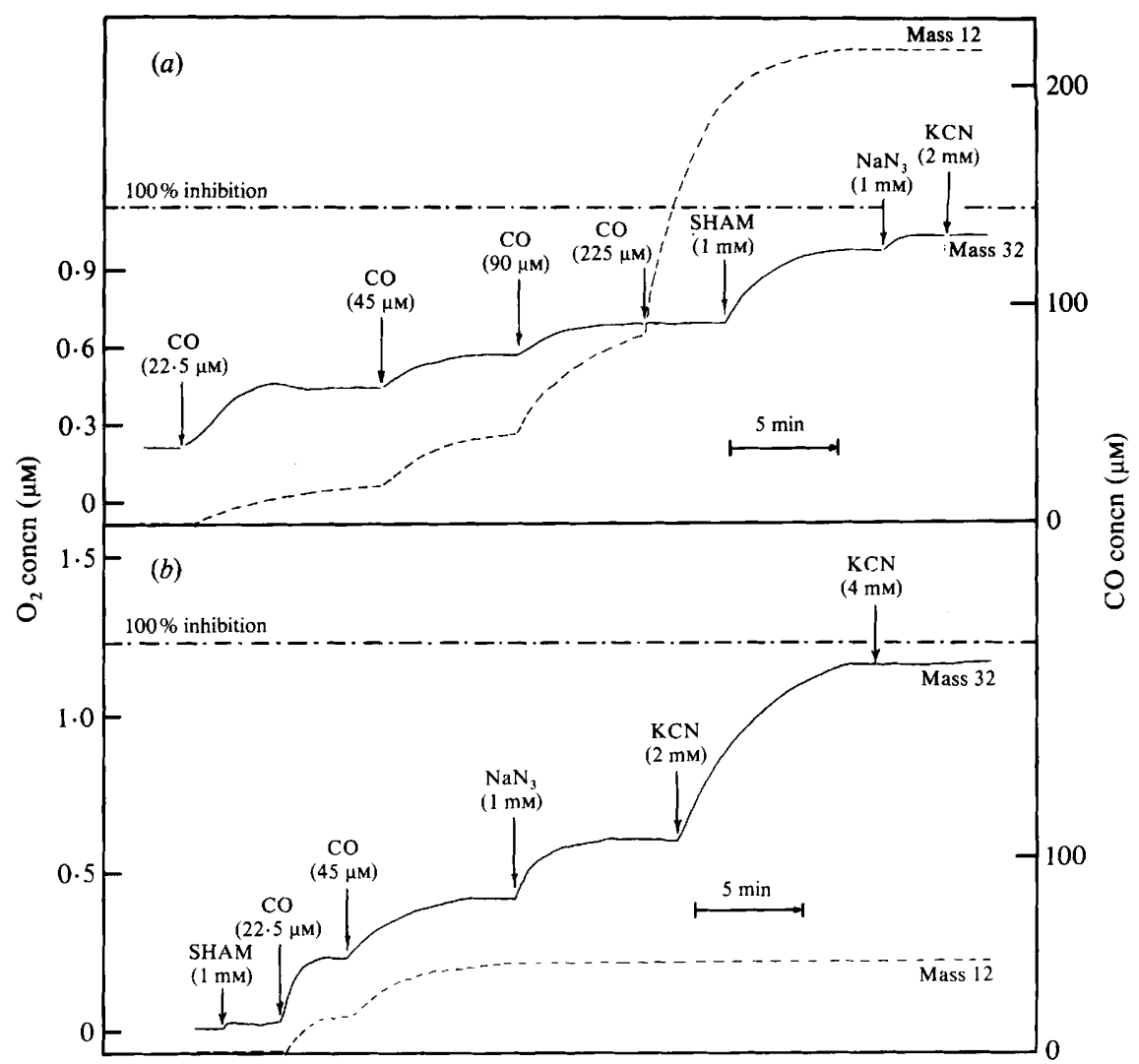

Fig. 2. Steady-state concentrations of $\mathrm{O}_{2}(-)$ and $\mathrm{CO}$ concentrations (--- ) in non-growing suspensions of Acanthamoeba castellanii in the open system measured by mass spectrometry. (a) Cells from an early-exponential phase culture $\left(5.6 \times 10^{5}\right.$ organisms $\left.\mathrm{ml}^{-1}\right)$ were washed twice and concentrated 2.5 -fold in $0.9 \% \mathrm{NaCl}$. (b) Cells were obtained in an identical way from a late-exponential phase culture $\left(1.6 \times 10^{6}\right.$ organisms $\left.\mathrm{ml}^{-1}\right)$ but were diluted by one-third with saline. The gas phase contained $0.125 \% \mathrm{O}_{2}$ in $\mathrm{N}_{2}$ throughout the experiments; $\mathrm{CO}\left(2.5 \%\right.$ in $\left.\mathrm{N}_{2}\right)$ was added as indicated into the gas stream entering the open system. The liquid volume was $4.5 \mathrm{ml}$. The results are typical of triplicate experiments.

To resolve further the contributions of different terminal oxidases to overall cellular respiration, measurements were made at low $\mathrm{O}_{2}$ concentrations, in order both to increase the effectiveness of competitive inhibition by $\mathrm{CO}$ (by increasing the $\mathrm{CO} / \mathrm{O}_{2}$ ratio), and to minimize the contribution of any oxidase with a low affinity for $\mathrm{O}_{2}$. Respiration of organisms from the early-exponential phase of growth (Fig. $2 a$ ) was almost completely inhibited in the presence of $225 \mu \mathrm{M}-\mathrm{CO}$ and $1 \mathrm{mM}-\mathrm{SHAM}$ when the $\mathrm{O}_{2}$ concentration was $0.75 \mu \mathrm{M}$. Addition of $1 \mathrm{mM}$-azide gave an extra $8 \%$ inhibition, but subsequent addition of cyanide ( $2 \mathrm{~mm}$ ) was without effect. However, in cells from late-exponential phase cultures (Fig. $2 b$ ), inhibition by SHAM, $\mathrm{CO}$ and azide at low $\mathrm{O}_{2}$ concentrations left a considerable residual respiration $(50 \%)$, which was cyanide-sensitive. The use of higher $\mathrm{CO}$ concentrations in this experiment gave a similar result. Changing the order of introduction of respiratory inhibitors gave similar results for both kinds of organisms (11 experiments). The inhibitory effect of $\mathrm{CO}$ was completely reversible in organisms exposed to this inhibitor for up to $40 \mathrm{~min}$. It is concluded that during the later phases of exponential growth the third terminal oxidase (azide-, $\mathrm{CO}_{-}$, and SHAM-insensitive), which has a low $\mathrm{O}_{2}$ affinity early in growth, becomes modified in its $\mathrm{O}_{2}$-binding properties or is replaced by a fourth oxidase which has a similar spectrum of 
inhibitor sensitivities. Oxidases which are cyanide-sensitive but azide- and SHAM-insensitive also occur in trypanosomes (Hill, 1978) and Tetrahymena pyriformis (Lloyd et al., 1980).

D. L. thanks members of the Institute of Biochemistry at Odense for their help and hospitality and $\mathrm{Mr} \mathrm{N}$. Williams and Mrs J. Williams for technical help.

\section{REFERENCES}

Degn, H., Lloyd, D. \& Hill, G. C. (editors) (1978). Functions of Alternative Terminal Oxidases. Oxford: Pergamon Press.

Degn, H., Lundsgaard, J. S., Petersen, L. C. \& OrMICKI, A. (1980). Polarographic measurement of steady state kinetics of oxygen uptake by biochemical samples. Methods of Biochemical Analysis 26, 47-77.

Edwards, S. W. \& Lloyd, D. (1977). Cyanideinsensitive respiration in Acanthamoeba castellanii. Changes in sensitivity of whole cell respiration during exponential growth. Journal of General Microbiology 103, 207-213.

Edwards, S. W. \& Lloyd, D. (1978a). Properties of mitochondria isolated from cyanide-sensitive and cyanide-stimulated cultures of Acanthamoeba castellanii. Biochemical Journal 174, 203-211.

Edwards, S. W. \& Lloyd, D. (1978b). Cyanideinsensitive respiration in Acanthamoeba castellanii. In Functions of Alternative Terminal Oxidases, pp. 31-37. Edited by H. Degn, D. Lloyd \& G. C. Hill. Oxford: Pergamon Press.
Hill, G. C. (1978). Characterization of the electron transport systems present during differentiation of African trypanosomes. In Functions of Alternative Terminal Oxidases, pp. 67-77. Edited by H. Degn, D. Lloyd \& G. C. Hill. Oxford: Pergamon Press.

Lloyd, D., Edwards, S. W., KRISTENSEN, B. \& DEGN, H. (1979). The effect of inhibitors on the oxygen kinetics of terminal oxidases of Acanthamoeba castellanii. Biochemical Journal 182, $11-15$.

Lloyd, D., Kristensen, B. \& Degn, H. (1980). The effect of inhibitors on the oxygen kinetics of terminal oxidases of Tetrahymena pyriformis ST. Journal of General Microbiology 121, 117-125.

Lloyd, D., Kristensen, B. \& Degn, H. (1981). Oxidative detoxification of hydrogen sulphide detected by mass spectrometry in the soil amoeba Acanthamoeba castellanii. Journal of General Microbiology 126, 167-170.

Petersen, L. C. (1977). The effect of inhibitors on the oxygen kinetics of cytochrome $c$ oxidase. Biochimica et biophysica acta 460, 299-307. 